\title{
A IMPORTÂNCIA DA BRASÍLIA MÉDICA
}

\author{
THE IMPORTANCE OF BRASÍLIA MÉDICA
}

Luiz Augusto Casulari e Lucilia Domingues Casulari da Motta

DOI - 10.5935/2236-5117.2015v52n3/4a01

Quando assumimos a editoria da Brasília Médica, no início da primeira administração de doutor Lairson Vilar Rabelo, existia um dilema como desafio - não recebíamos artigos para publicação porque a revista não era publicada, e a revista não era publicada porque não recebia artigos.

Utilizamos algumas estratégias que foram vitoriosas e que podem ser usadas na atual situação da Brasília Médica para inverter esse momento delicado.

Uma estratégia foi solicitar a cada sociedade de especialidade a edição de um fascículo. Isso foi feito com a Sociedade de Endocrinologia ${ }^{1}$ e com aquela de Pneumologia. ${ }^{2}$

Outra estratégia foi incentivar a publicação de estudo de caso. As revistas mais importantes não aceitam esse tipo de artigo porque diminuem seu fator de impacto. Esses artigos têm pequeno número de citações ou quase nunca são citados. Atualmente, para preencher esse espaço, foram criadas várias revistas com 0 único objetivo de publicar esse tipo de estudo, o que muitíssimo tem ajudado pacientes com doenças raras e seus cuidadores, inclusos os médicos. Observamos que fatores de impactos são importantes na atenção aos valores dos periódicos científicos, mas a importância de fornecer conhecimentos para salvar vidas desses doentes especiais precisa ser também atendida.

Uma terceira estratégia, que reputamos como interessante, foi convidar autores que tivessem expertise no assunto. Muitas vezes, não tínhamos retorno, mas aqueles que atenderam à nossa solicitação contribuíram com artigos muito interessantes. Vários deles são referências para aquele assunto. Citaremos alguns pela importância que reputamos terem adquirido.

Um estudo original enviado pelo grupo do professor Luiz Claudio Gonçalves de Castro, apresentou os excelentes resultados da infusão cíclica intravenosa de pamidronato dissódico no tratamento da osteogênese imperfeita em crianças e adolescentes. ${ }^{3} 0$ editorial da professora Marise Lazaretti Castro foi muito feliz: "Quando o médico faz diferença".4
Luiz Augusto Casulari - médico, doutor pela Università degli Studi di Milano, Itália, orientador dos cursos de pós-graduação em Ciências da Saúde da Universidade de Brasília e Escola Superior em Ciências da Saúde

Lucilia Domingues Casulari da Motta - médica, doutora pela Università degli Studi di Milano, Itália, professora aposentada de Ginecologia e Obstetrícia da Universidade de Brasília

Correspondência: Luiz Augusto Casulari. CLINEN - SCN quadra 1, bloco F, Edifício America Office Tower, sala n. ${ }^{0} 1.105$, CEP 70711906, Brasília-DF.

Internet: lacasulari@unb.br ou roxomotta@ambr.org.br

Conflito de interesses: nada a declarar.

Existe, ainda hoje, uma discussão a propósito de a mortalidade por câncer de próstata não ter se alterado nos últimos anos. Assim, tivemos o artigo de J. V. Gerhold e colaboradores, de Zaragoza, Espanha, que examinaram de forma brilhante esse aspecto. ${ }^{5}$ Neste sentido, L. D. Castiel fez o editorial em que avalia os riscos e os exageros da promoção da saúde. ${ }^{6}$

O suicídio é preocupação constante para todos, desde o paciente em si e sua família, à equipe médica envolvida no atendimento do evento. $\mathrm{O}$ artigo de M. C. L. Neves e colaboradores é referência no aconselhamento do Conselho Federal de Medicina para a condução dessa situação crítica. ${ }^{7}$

O abuso de drogas é situação devastadora para o paciente e sua família, além do insucesso em seu tratamento ser frustrante até os dias atuais. A. D. Galeassi e V. Santos examinaram esse assunto de maneira muito competente no artigo publicado em nossa revista. ${ }^{8}$ Complementando esse artigo, D. A. Baltieri fez o editorial da revista a propósito dessa difícil abordagem. ${ }^{9}$

O tratamento de doenças cardiovasculares envolve vários tipos de drogas. A diminuição de concentração 
sanguínea de colesterol é considerada como evento de fundamental importância. Isso é mostrado pela prescrição cada vez mais frequente de estatina. Contudo, muitas vezes existem conflitos de interesses entre os responsáveis pelas recomendações das sociedades médicas e a indústria farmacêutica. Isso foi motivo de um artigo editorial da Brasília Médica. ${ }^{10}$ Além disso, o autor francês Michel de Lorgeril atraiu atenção sobre a possivel associação de câncer com a baixa do colesterol, e a estatina poderia estar envolvida. ${ }^{11}$

A controversa suplementação de cálcio em pacientes osteoporóticos e o aumento de riscos cardiovasculares foi muito bem examinada no artigo de V. Z. C. Borba e colaboradores. $^{12}$

O uso da maconha como medicamento está cada vez mais atual. A Brasília Médica publicou dois artigos em que foram examinados de modo cientificamente correto esse importante assunto, abordado por F. A. Moreira e colaboradores ${ }^{13}$ e Orlandi-Mattos \& Carlini. ${ }^{14}$ O primeiro artigo mereceu o editorial do professor E. A. Carlini, um dos maiores pesquisadores do assunto no Brasil. ${ }^{15}$

A fitoterapia tem papel importante na vida do brasileiro. Bezerra e Silveira apresentaram um compreensivo artigo de quando e como usar as plantas medicinais brasileiras. ${ }^{16}$ Nesse mesmo sentido, Espinosa-Darvenne atraiu atenção a propósito das plantas do cerrado como fonte de descobertas de novos medicamentos. ${ }^{17}$ Dorea e Costa publicaram novos fatos e velhos mitos sobre o café. ${ }^{18}$

Uma visão médica, não policialesca, da pedofilia foi apresentada por D. A. Baltieri, ${ }^{19}$ isto é, o pedófilo deve ser considerado um doente que necessita de tratamento. 0 editorial de Kunzler e Braga aprofundou esse aspecto médico do artigo. ${ }^{20}$

O potencial do uso da terapia cognitiva comportamental no tratamento do transtorno obsessivo-compulsivo foi apresentado por L. Kunzler. ${ }^{21}$

O enigma do placebo como medicamento foi apresentado por F. Martins ${ }^{22}$ e mereceu um excelente editorial de dois ícones da pesquisa em Brasília: B. Beraldo e M. G. Pereira. ${ }^{23}$ Mais recentemente, D. B. Greco e R. Parizi fizeram um editorial com exame do aspecto ético do placebo nas pesquisas clínicas. ${ }^{24}$

O uso de células imortalizadas na pesquisa básica cada vez mais ocupa o espaço dos modelos animais. Em artigo publicado nesta revista, R. Maggi e colaboradores, de Milão, Itália, mostraram a importância das células produtoras de hormônio liberador das gonadotrofinas na compreensão de aspectos fisiológicos e patológicos da secreção das gonadotrofinas. ${ }^{25}$ Esse artigo mereceu o editorial de F. A. R. Neves e A. Lofrano-Porto, dois pesquisadores da Universidade de Brasília. ${ }^{26}$

Uma capa da revista Veja, em que mostra o rosto do assassino do cartunista Glauco e de seu filho, causounos indignação por não preservar o doente como somos habituados a fazer ao descrever algum caso médico. Fazia alguma associação com o crime do uso da ayahuasca, consumida em ritual religioso na chácara do cartunista. Atendendo ao nosso convite, o pesquisador R. G. Santos fez um artigo que mostrou a farmacologia dessa planta. ${ }^{27}$ A Universidade de Brasília, atualmente, desenvolve pesquisas em várias áreas para entender melhor o que é a ayahuasca.

Um artigo que causou polêmica até fora do foco médicocientífico versou a propósito dos anorexígenos e da sibutramina. Fizemos um artigo, como ponto de vista, em que mostrávamos as incoerências dos defensores dessas drogas para o tratamento da obesidade. Nossa expectativa era de que os citados enviassem algum texto contestando cientificamente nossos argumentos. Contudo, fomos surpreendidos com processos na justiça, feito pelo presidente do Conselho Federal de Medicina, e outro no Comitê de Ética da Sociedade Brasileira de Endocrinologia e Metabolismo. 0 primeiro foi retirado com pedido de desculpas, pessoalmente, por aquele mesmo presidente, e o outro fui informado, extraoficialmente, que tinha sido arquivado. ${ }^{27}$

Um importante fascículo, publicado como suplemento, foi "Educação em Ética na Pesquisa: o Desafio Para a Formação de Jovens Cientistas", de um simpósio que ocorreu na Universidade de Brasília, teve autores como Dirce Guilhen, Dirceu Bartolomeu Greco, Pedro Luiz Tauil entre outros. ${ }^{29}$

Contudo, muitos desses textos foram perdidos e não são mais acessados no portal da Associação Médica de Brasília, o que é lamentável. Mas essa memória pode ser recuperada porque deixamos a coleção praticamente completa em forma impressa. É necessário que seja recuperado esse acervo, já que cada vez menos pessoas, nos dias atuais, vão às bibliotecas para procurar revistas. Se estas não estiverem on-line, muito dificilmente serão consultadas. Então, um dos desafios da atual administração é recuperar isso e a indexação da revista no Lilacs. Essa é uma das dificuldades que tivemos, ou seja, as pessoas não querem publicar na revista porque perdeu a pequena importância que tinha para 
os currículos dos autores. Hoje, a Brasília Médica é classificada como B5 pela Capes, ou seja, é de pouca importância no universo científico.

Com este fascículo, pretendemos dar um pequeno passo para recuperar o prestígio da revista. Como endocrinologistas, pensamos ser um exemplo para as outras especialidades fazerem o mesmo. São mais de cinquenta especialidades médicas atuantes na Associação Médica de Brasília. Se cada uma se encarregar de fazer um fascículo de especialidade, em pouco tempo, haverá o retorno da indexação no Lilacs. Para quem pretendia passar ao Scielo e ao Redalic, a queda foi enorme. Mas podemos reagir e voltar a ter um patamar mais relevante.

Aos que pretendem ajudar neste processo, temos um alento muito importante - a atual diretoria da $\mathrm{AMBr}$, cuja presidência é ocupada por doutor Ognev Meireles Cosac, tem mostrado que está disposta a dar todas as condições para que tenhamos êxito nessa caminhada.

\section{REFERÊNCIAS}

1. Gomes ND (editor). Endocrinologia e breve revisão sobre endocrinopatias mais frequentes. Brasília Med. 2008;45(3).

2. Feitosa PHG (editor). Doenças do trato respiratório. Brasília Med. 2007;44(4).

3. Dos Santos CCT, Bezzerra ACA, da Cruz CB, Martins CES, de Castro LCG. Resposta clínica de crianças e adolescentes com osteogênese imperfeita à terapia com infusão cíclica intravenosa da pamidronato dissódico. Brasília Med. 2009;46(4):309-16.

4. Castro ML. Editorial. Quando o médico faz diferença. Brasília Med. 2009;46(4):307-8.

5. Gerhold JV, Poves VC, Calero DV. Las consecuencias del sobrediagnóstico y el sobretratamiento en el cáncer de próstata. Brasília Med. 2011;48(2):175-83.

6. Castiel LD. Os riscos e os exageros da promoção da saúde. Brasília Med. 2011;48(1):1-3.

7. Neves MCL, Meleiro AMAS, Gomes F, Silva AC, Correa H. Suicídio: fatores de risco e avaliação. Brasília Med. 2014;51(1):66-73. DOI: 10.14242/2236-5117.2014v 51n1a249p66.

8. Galassi AD, Santos V. O abuso de drogas: desafios e opções para a prática do profissional de saúde no Brasil. Brasília Med. 2013;50(1):51-7.

9. Baltieri DA. Prevenção e tratamento de abuso e dependência de álcool e outras drogas: ingredientes insalubres e propostas inovadoras. Brasília Med. 2013;50(1):3-5.

10. Casulari LA, Motta LDC. Editorial. Influência da indústria nas recomendações das sociedades médicas: a propósito do uso da estatina. Brasília Med. 2013;50(4):286-7.

11. Lorgeril M. Colesterol, tratamento anticolesterol e câncer. Brasília Med. 2010;47(3):356-60.

12. Borba VZC, Ramos CS, Bianchet LC. Suplementação de cálcio em pacientes osteroporóticos e aumento de risco cardiovascular. Brasília Med. 2011;48(2):184-7.

13. Moreira FA, Viana TG, Santos-Almeida AF, Vilela LR, Gobina PH, Aguiar DC. Developing new medicines from Cannabis sativa: challenges and perspectives. Brasília Med. 2011;48(3):27783.

14. Orlandi-Mattos PE, Carlini ELA. Cannabis sativa C (maconha): medicamento que renasce? Brasília Med. 2011;48(4):40915.

15. Carlini EA. A maconha como medicamento. Brasília Med. 48(3):238.

16. Bezerra AC, Silveira D. Drogas vegetais: uma antiga nova forma de utilização de plantas medicinais. Brasília Med. 2010;48(2):219-37.

17. Espindola-Darvenne LS. Cerrado: fonte de descobertas de novos medicamentos. Brasília Med. 2007;44(3):193-8.

18. Costa TH, Dorea JC. Novos fatos e velhos mitos sobre o café. Brasília Med. 42(3/4):75-80.

19. Baltieri DA. Pedofilia como transtorno comportamental psiquiátrico crônico e transtornos comportamentais assemelhados. Brasília Med. 2013;50(2):122-31.

20. Kunzler LS, Braga ARM. Pedofilia, doença crônica, causa ou consequência: prevenção, identificação precoce e tratamento adequado. Brasília Med. 2013;50(2):85-8.

21. Kunzler LS. A contribuição da terapia cognitiva para o tratamento do transtorno obsessivo-compulsivo. Brasília Med. 2008;45(1):30-40.

22. Martins F. Placebo: eficácia e desqualificação na clínica cotidiana. Brasília Med. 44(2):112-21.

23. Beraldo P, Pereira MG. Editorial. 0 poder do placebo. Brasília Med. 44(2):83-6.

24. Greco DB, Parizi R. Bioética e uso de placebo em pesquisas clínicas. Brasília Med. 2014;51(1):1.

25. Maggi R, Dondi D, Piva F. Biologia de neurônios hipotalâmicos produtores de hormônio liberador das gonadotrofinas: novas informações sobre o uso de células imortalizadas secretoras desse hormônio. Brasília Med. 2006;43(1/4):40-7.

26. Lofrano-Porto A, Neves FAR. As bases moleculares da medicina: da bancada do laboratório à beira do leito. Brasília Med. 2006;43(1/4):4.

27. Santos RG. The pharmacology of ayahuasca: a review. Brasília Med. 2010;47(2):187-94.

28. Casulari LA, da Motta LDC. Reflexões sobre os conflitos de interesses entre médicos e a indústria farmacêutica: a propósito da sibutramina. Brasília Med. 2011;48:308-13. DOI 10.14242/2236-5117.2013v48n3ap.

29. Educação em ética na pesquisa: o desafio para a formação de jovens cientistas. III Oficina de Ética em Pesquisa. IX Semana de Extensão da Universidade de Brasília. XV Congresso de Iniciação Científica da Universidade de Brasília. Brasília Med. 2009;46(Suplemento 1). 